\title{
Capsule Commentary on Bloom-Feshbach et al., Health Literacy in Transitions of Care: An Innovative Objective Structured Clinical Examination for Fourth Year Medical Students in an Internship Preparation Course
}

\author{
Deborah P. Jones, MD MPH \\ Columbia University College of Physicians \& Surgeons, New York, NY, USA.
}

$J$ Gen Intern Med 31(2):227

DOI: $10.1007 / \mathrm{s} 11606-015-3541-\mathrm{x}$

(c) Society of General Internal Medicine 2015

A chieving the Healthy People 2020 goal of health equity in the U.S. will require better training on safe hospital discharges and communication with low-literacy populations. ${ }^{1,2}$ Bloom-Feshbach et al. present their experience and data collected from a new residency-readiness curriculum to teach and assess communication skills during a high-risk discharge scenario with a patient with low literacy. ${ }^{3}$ The vaguely described peer-led workshop emphasized widely taught approaches such as 'teach-back', ${ }^{4}$ and was the basis of behavioral assessment in the single OSCE using trained, non-standardized actors. Interpretation of their findings is limited — of both the "natural experiment' assessing workshop efficacy and the generalizability and reliability of skill assessment using their non-validated behavioral checklist. Nevertheless, institutions in need of similar curriculum will find value in their novel approach for assessing pre-residency competency in safe discharge communication.

The authors identify important areas of focus for training. Despite workshop participation, students screened patients on literacy level only $50 \%$ of the time and wrote discharge instructions at a much higher level (10th grade) than recommended (6th grade). It is not clear whether the observed mean OSCE score of 14/17 would be sufficient in a real-world setting, nor is there a description of what behaviors were most often missed. The OSCE performance checklist was given back to students; an enhanced program would incorporate personalized coaching and reflection. Whether the reassuring post-OSCE student attitude and confidence in low health literacy communication either reflects the curriculum's impact or correlates with student skill is uncertain.
The take-home message is that skills in communication and an entrustable professional activity (EPA) can be assessed simultaneously in an OSCE, and can help ensure residency readiness for immediate remediation opportunities. Ideally, such a program will remind departing graduates that good communication will not only be integral to their job, but will also enhance their own empathy and emotional resilience ${ }^{5}$ and ultimately improve patient outcomes. The financial and time investment in reliable OSCE programs is substantial and justifies more finessed evaluation of curriculum, building on the work presented here.

Corresponding Author: Deborah P. Jones, MD MPH; Columbia University College of Physicians Surgeons, New York, NY 10021, USA (e-mail:dpj6@columbia.edu).

\section{Compliance with ethical standards:}

Conflict of Interest: The author has no conflicts with this article.

\section{REFERENCES}

1. Healthy People 2020 [Internet]. Washington, DC: U.S. Department of Health and Human Services, Office of Disease Prevention and Health Promotion [cited September 28, 2015]. Available from: http://www.healthypeople.gov/.

2. Yin HS, Jay M, Maness L, Zabar S, Kalet A. Health literacy: an educationally sensitive patient outcome. J Gen Intern Med. 2015;30(9):1363-1368. doi:10.1007/s11606-015-3329-z.

3. Bloom-Feshbach K, Casey D, Schulson L, Gliatto P, Giftos J, Karani R. Health literacy in transitions of care: an innovative objective structured clinical examination for fourth year medical students in an internship preparation course. J Gen Intern Med. 2015. doi:10.1007/s11606-0153513-1.

4. Kripalani S, Jacobson K, Brown S, Manning K, Rask KJ, Jacobson TA. Development and implementation of a health literacy training program for medical residents. Medical Education Online, [S.1.], v. 11, dec. 2006. ISSN 1087-2981. Available at: <http://med-ed-online.net/index.php/meo/article/view/4612>. Date accessed: 26 Sep. 2015. doi:10.3402/meo.v11i.4612.

5. Krasner MS, Epstein RM, Beckman H, Suchman AL, Chapman B, Mooney CJ, Quill TE. Association of an educational program in mindful communication with burnout, empathy, and attitudes among primary care physicians. JAMA. 2009;302(12):1284-1293. doi:10.1001/jama.2009.1384. 